\title{
Biotechnologically relevant features of gluconic acid production by acetic acid bacteria
}

\author{
Isidoro García-García, ${ }^{1}$ Ana M. Cañete-Rodríguez, ${ }^{1}$ Inés M. Santos-Dueñas, ${ }^{1}$ \\ Jorge E. Jiménez-Hornero, ${ }^{2}$ Armin Ehrenreich, ${ }^{3}$ Wolfgang Liebl, ${ }^{3}$ \\ Teresa García-Martínez, ${ }^{4}$ Juan C. Mauricio ${ }^{4}$
}

\begin{abstract}
${ }^{1}$ Department of Inorganic Chemistry and Chemical Engineering, Marie Curie Building, Campus of Rabanales, University of Cordoba, Spain; ${ }^{2}$ Department of Computing and Numerical Analysis, Leonardo da Vinci Building, Campus of Rabanales, University of Cordoba, Spain; ${ }^{3}$ Department of Microbiology, Technical University of Munich, Freising-Weihenstephan, Germany; ${ }^{4}$ Department of Microbiology, Severo Ochoa Building, Campus of Rabanales, University of Cordoba, Spain
\end{abstract}

\begin{abstract}
The many uses of gluconic acid and some of its salts are arousing increasing interest in these compounds and in their production levels. Although gluconic acid and gluconates can be obtained chemically, they are currently almost exclusively biotechnologically produced, mostly by fungus based methods. There is, however, an ongoing search for alternative microorganisms to avoid the problems of using fungi for this purpose and to improve the productivity of the process. Especially promising in this respect are acetic acid bacteria, particularly Gluconobacter strains. This paper discusses the main variables and operating con-
\end{abstract}

Correspondence: Isidoro García-García, Departamento de Química Inorgánica e Ingeniería Química, Facultad de Ciencias, Campus Universitario de Rabanales, Universidad de Córdoba, Ctra. (a) de Madrid, km 396, 14071 Córdoba, Spain.

Tel.: +34.957.218589 - Fax: +34.957.218589.

E-mail: iq1gagai@uco.es

Key words: Gluconic acid; acetic acid bacteria; Gluconobacter; optimization.

Acknowledgments/Funding: the authors are grateful to Spain's Ministry of Science and Innovation for partially funding this study within the framework of the project AGL2010-22152-CO3-03 and to University of Córdoba within the framework of Programa Propio 2016 Mod.4-1.

Contributions: IG-G and AMC-R conceived and wrote the article; IMS$\mathrm{D}$ and JEJ-H reviewed and coordinate the format; AE, WL, TG-M and JCM reviewed biochemical and microbiological aspects.

Received for publication: 9 December 2016.

Revision received: 26 January 2017.

Accepted for publication: 3 February 2017.

This work is licensed under a Creative Commons Attribution NonCommercial 4.0 License (CC BY-NC 4.0).

(C) Copyright I. García-García et al., 2017

Licensee PAGEPress, Italy

Acetic Acid Bacteria 2017; 6:6458

doi:10.4081/aab.2017.6458 ditions to be considered in optimizing gluconic acid production by Gluconobacter.

\section{Introduction}

Gluconic acid (GA) and some of its salts are widely used by various industries among which food, building, textile and pharmaceutical ones can be highlighted. ${ }^{1}$ The fact that they are listed among the most produced chemicals ${ }^{2}$ testifies to their importance. All the products in this list have been the subject to careful study in order to avoid potential risks for humans and the environment, at present, GA and its salts are classified as low-hazard substances. ${ }^{3}$

A total amount of 65,000 to 100,000 metric tons of GA and gluconates is produced each year, ${ }^{3,4}$ virtually exclusively via fermentation processes. The production and uses of GA and its salts are described in detail elsewhere. ${ }^{1,5-11}$ Briefly, these substances are used as ingredients of personal care products, pharmaceuticals, chelating agents (e.g., for calcium in the building industry), industrial cleaners and metal surface treatments ${ }^{8}$ as well as stabilizing agents for textile bleachers. ${ }^{3}$ Additionally, because of their prebiotic properties, GA and its major derivatives are being used as additives in foods and drinks and are considered as key components in the development of new beverages. ${ }^{1,12-14}$ Despite their flexibility and the large amounts used, no potential hazards justifying further investigation of their safety have so far been identified.

The most common biotechnological process for GA production is based on fungi and uses Aspergillus niger. This microorganism yields the GA via D-glucono- $\delta$-lactone as intermediate reaction product. Specifically, the enzyme glucose oxidase catalyses the conversion of glucose to the lactone, which subsequently gives GA (fast at either acidic or alkaline conditions and slow at neutral $\mathrm{pH}$; also the hydrolisis of glucono- $\delta$-lactone is enzymatically facilitated by lactonase, specially required at neutral $\mathrm{pH}$ ). The process requires carefully adjusting the $\mathrm{pH}$ of the medium and ensuring an adequate supply of oxygen. ${ }^{8}$ In fact, the high oxygen demand of the biotransformation process, and the typical difficulties of homogenizing a highly viscous medium such as one with fungal mycelia, considerably raise operational costs and hinder homogeneous distribution of dissolved oxygen in the culture 
medium. ${ }^{15}$ Also, the $\mathrm{pH}$ of the medium should be controlled in the range 4.5-7.0 because a lower value triggers the tricarboxylic acid cycle and leads to citric rather than GA. ${ }^{8}$ These difficulties have boosted a search for alternative microorganisms capable of producing $\mathrm{GA}^{1}$ (particularly acetic acid bacteria).

\section{Acetic acid bacteria}

Belonging to the family Acetobacteraceae, acetic acid bacteria (AAB) comprise 19 genera and 87 species, ${ }^{16}$ among which representatives of Gluconobacter are especially prominent with regard to GA production. ${ }^{11,17-22}$ Similarly to fungi - albeit with different enzymes -, these bacteria oxidize glucose virtually stoichiometrically to GA via glucono- $\delta$-lactone. ${ }^{21}$ The oxidation reaction occurs in the bacterial periplasm and is effected by a membrane-bound pyrroloquinoline quinone-dependent glucose dehydrogenase (PQQ-GDH) located in the outer side of the cytoplasmic membrane; glucose and the resulting GA may undergo other biotransformation reactions depending on the particular operating conditions..$^{21,23-34}$

One of the most remarkable features of Gluconobacter spp is their incomplete oxidation metabolism, by which a large amount of glucose can be rapidly oxidized to GA for energy generation while simultaneously acidifying the medium; ${ }^{28,34,35} \mathrm{GA}$ thus formed can be further converted into various ketoacids. ${ }^{36}$ Although glucose, gluconates and ketogluconates can be used by the microorganism $^{25,35,37}$ (Figure 1), all these pathways are strongly influenced by some variables such as $\mathrm{pH}$, the glucose concentration in the culture medium, the amount of dissolved oxygen and the presence of cal- cium ions. It is therefore essential to carefully examine the influence of these variables in order to optimize the operating conditions for optimal conversion of glucose to GA and protection of the product from further reaction.

\section{Optimum conditions for gluconic acid production}

\section{Influence of $\mathrm{pH}$ and the initial concentration of sub-} strate

Olijve and $\mathrm{Kok}^{25}$ examined the influence of $\mathrm{pH}$ on GA production by Gluconobacter oxydans (ATCC $621 \mathrm{H}$ ) in two different culture media and found the assimilative pentose phosphate pathway to be virtually completely inhibited below $\mathrm{pH} 3.5-4$. Since the formation of GA as the fermentation process develops decreases the $\mathrm{pH}$ of the medium, it seems reasonable to either control this variable or keep it below the inhibitory level. This is logical if one considered the metabolic features of the genus Gluconobacter and the action of its enzymes - some of which are illustrated in Figure 1. Such enzymes ${ }^{36-38}$ are either dehydrogenases bound to the cytoplasmic membrane or soluble NAD(P)-dependent cytosolic oxidoreductases. The former are usually highly active at acid $\mathrm{pH}$ (especially in the range 3.0-6.0), whereas the activity of the latter is more prominent in alkaline media (particularly at $\mathrm{pH} 8.0-11.0$ ). Olijve and $\mathrm{Kok}^{25}$ also found the initial concentration of glucose in the medium to be strongly influential on the oxidation of glucose and gluconate through the pentose phosphate pathway; specifically, this pathway was considerably less important - and led to GA rapidly accumulating in the medium - at glucose concentrations

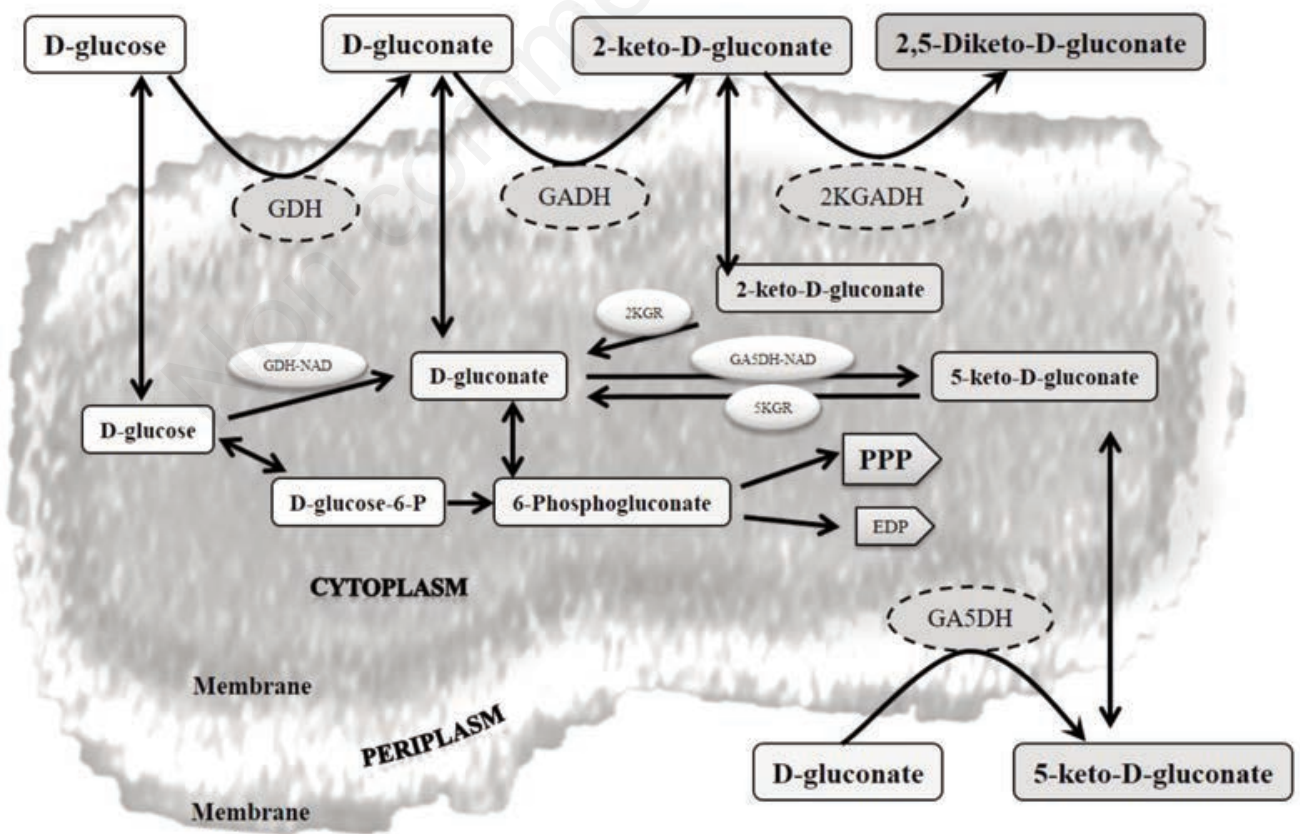

Figure 1. Glucose metabolism in Gluconobacter. GDH, PQQ-dependent D-glucose dehydrogenase (in the cytoplasmic membrane, EC 1.1.5.2) and (GDH-NAD) NADP-dependent D-glucose dehydrogenase (in the cytoplasm EC 1.1.1.47); GADH: FAD-dependent Dgluconate 2-dehydrogenase (EC 1.1.99.3); 2KGADH: FAD-dependent 2-keto-D-gluconate dehydrogenase (EC 1.1.99.4); GA5DH, PPQ-dependent D-gluconate 5-dehydrogenase (in cytoplasmic membrane) and (GA5DH-NAD) NADP-dependent D-gluconate 5dehydrogenase (in cytoplasm EC 1.1.1.69); 2KGR: 2-keto-D-gluconate reductase (EC 1.1.99.3); 5KGR: 5-keto-D-gluconate reductase (EC 1.1.1.69). PPP, Pentose Phospate Pathway. EDP, Entner Doudoroff Pathway. 
above $0.9-2.7 \mathrm{~g} / \mathrm{L}$ (5-15 mM); at lower concentrations, the share of the uptake pathway is more prominent. This microbial behaviour, which is closely related to substrate availability in the medium, is seemingly used by $\mathrm{AAB}$ to compete with other microorganisms. ${ }^{28,34,35}$ In fact, if AAB are present in an environment rich in carbon sources that can be rapidly depleted by other competing microorganisms, they cause the fast, imcomplete oxidation of such sources (e.g., by converting sugars into sugar acids, which are less readily used by many other microorganims, and facilitating their accumulation as carbon sources for subsequent use). Simultaneously, AAB lower the $\mathrm{pH}$ and increase the inhibitory effects of the accumulated acids on other microorganisms. Obviously, when the fermentation medium contains little glucose as substrate, $\mathrm{AAB}$ must inevitably assimilate a significant part of it for biomass synthesis. Therefore, ensuring efficient GA production with $\mathrm{AAB}$ entails using relatively high initial concentrations of glucose - above the previously mentioned concentration range in any case.

Due to the activity of the membrane bound dehydrogenases forming GA from higher concentrations of glucose, in the absence of $\mathrm{pH}$ control during the fermentation process, the potential decrease in $\mathrm{pH}$ will be directly related to the initial glucose concentration. Accordingly, the higher is the substrate concentration, the higher can be the amount of GA formed and the lower the final $\mathrm{pH}$ as a result. However, the concentration of glucose by itselt also seems to inhibit in some extent the activity of $G$. oxydans. Thus, Velizarov and Beschkow ${ }^{31,32}$ used G. oxydans NBIMCC 1043 grown on a synthetic medium containing variable concentrations of glucose from 5 to $250 \mathrm{~g} / \mathrm{L}$ and found the maximum specific growth rate $\left(\mu_{m}\right)$ and the final GA yield $\left(Y_{\mathrm{GA} / \mathrm{G}}\right)$ to be unequivocally related to the initial concentration of glucose. In fact, increasing glucose concentration up to $90 \mathrm{~g} / \mathrm{L}$ led to increased $\mu_{m}$ values up to a maximun of $0.39 \mathrm{~h}^{-1}$ with $Y_{\mathrm{GA} / \mathrm{G}}=90 \%$; however, higher glucose concentrations inhibited its conversion, as was reflected by long lag phases, and diminished $\mu_{m}$ and $Y_{\mathrm{GA} / \mathrm{G}}$ values. The longer lag phases can be ascribed only to the presence of high glucose levels and, in the absence of $\mathrm{pH}$ control, the diminished values for the maximum specific growth rates and final GA yields to the synergic effect between the high concentrations of glucose and the inhibition due to the GA by the decrease of the $\mathrm{pH}$. Cell growth and GA formation were virtualy stopped altogether below $\mathrm{pH}$ 2.0.

It is important to remind the growth behaviour of this microorganim; G. oxydans ${ }^{35}$ is believed to involve two growth stages depending on whether incomplete oxidations or the assimilation of glucose and gluconate prevails. The first pathway involves fast, incomplete oxidation of glucose and hence results in low growth yield of cells on glucose. In the second stage, once glucose has been virtually exhausted, incompletely oxidized substrates from the previous stage are assimilated; although slower than the previous stage, this one leads to higher substrate-based growth yields and hence from this perspective to more efficient use of the substrate by the microorganism. As a rule, cell growth is directly related to glucose uptake and GA accumulation during the first stage. ${ }^{13,39}$

Velizarov and Beschkow ${ }^{32}$ examined the potential inhibitory effect of GA on cell growth and its own production by adding different amounts of the acid from 2.8 to $138 \mathrm{~g} / \mathrm{L}$ to the initial medium; they immediately identified the occurrence of lag phases the duration of which increased with increasing concentration of GA added to the medium. However, the inhibitory effect was seemingly the result of the acid medium - the $\mathrm{pH}$ decreased with increasing amount of GA added.

Also, Krajewski et al. ${ }^{40}$ demonstrated strong negative effects of gluconate (and ketogluconate) formation from glucose by the analysis of mutant strains of G. oxydans N44-1 whose gene for membrane-bound glucose dehydrogenase was inactivated. This mutant no longer produced GA or ketogluconates from glucose, but revealed increased carbon dioxide formation and increased growth rate and growth yield. If additionally the gene for cytoplasmic glucose dehydrogenase was knocked out, the growth rate and growth yield was even further increased by up to $78 \%$ and $271 \%$, respectively, compared to the parental strain.

\section{Influence of the formation of ketoacids}

As can be seen from Figure 1, GA can be further oxidized to ketogluconates in a rapid manner in the periplasm. Specifically, GA can be converted into 2-ketogluconate (2-KGA) or 5-ketogluconate (5-KGA) competitively by two types of oxidizing enzymes bound to the cytoplasmic membrane, namely: ${ }^{35,36}$ FAD-dependent D-gluconate 2-dehydrogenase (FAD-GADH) ${ }^{41,42}$ for $2-\mathrm{KGA}$ and PQQ-dependent D-gluconate 5-dehydrogenase (PQQ-GLDH) ${ }^{38}$ for 5-KGA. Some strains allow 2-KGA to be further converted into 2,5-diketogluconic acid (2,5-DKGA) by FAD-dependent 2-ketoD-gluconate dehydrogenase (FAD-2KGADH). Also, under favourable conditions, $2-\mathrm{KGA}$ and 5-KGA in the medium can be assimilated by the microorganism ${ }^{35,38}$ and converted to gluconate in the cytoplasm. Ketoacids may thus be part of the abovedescribed microbial strategy of AAB involving incomplete oxidation of the substrate. Perhaps the ketoacids are not readily utilized by other microorganisms sharing their habitat with Gluconobacter spp., which would imply that (in addition to the energetic benefit they have) the oxidation of glucose to ketoacids may be a strategy of the AAB to withdraw the glucose from competing organisms.

The extent to which gluconates are oxidized to ketogluconates is difficult to assess because it depends on the particular strain and operating conditions. In any case, in the next two sections the main variables afecting this issue will be discussed.

\section{Influence of $\mathrm{pH}$ and the presence of $\mathrm{CaCO}$}

In experiments with $G$. oxydans ATCC $621 \mathrm{H}$ and no $\mathrm{pH}$ control - which led to a rapid drop below $\mathrm{pH} 3$ - or adjustment to $\mathrm{pH}$ 2.5 from the start, Olijve and $\mathrm{Kok}^{25}$ and Weenk et al. ${ }^{43}$ found glucose to be rapidly oxidized virtually quantitatively to GA without formation of any ketoacids. On the other hand, using a fixed $\mathrm{pH}$ of 5.5 or adding $\mathrm{CaCO}_{3}$ to the medium led to the formation of $2-\mathrm{KGA}$ and 5-KGA once virtually all glucose had been used. All eleven Gluconobacter strains studied behaved identically except for slight differences among the results. ${ }^{43}$

In continuous operation experimens with $G$. oxydans ATCC 621 and G. oxydans IFO 3290 under no $\mathrm{pH}$ control - which led to a $\mathrm{pH}$ of about 2.5 in the steady state -, Seiskari et al. ${ }^{44}$ succeeded in obtaining GA as the main oxidation product over a period of at least 6 months. However, raising the glucose concentration in the medium to ca. $200 \mathrm{~g} / \mathrm{L}$ inhibited to some extent GA formation which is consistent with the results of Velizarov and Beschkov. ${ }^{31}$ Again, a decreased concentration of glucose in the steady state favoured the formation of 2-KDG and 5-KGA at the expense of GA. Qazi et al. ${ }^{45}$ used G. oxydans ATCC 9937 and, unlike Weenk et al. ${ }^{43}$ found the best acidity conditions for 2,5-DKGA to be $\mathrm{pH}<$ 3.5 and the effect of $\mathrm{pH}$ to be even more marked than that of the glucose concentration. Also, they recommended using a slightly higher $\mathrm{pH}$ at the beginning in order to facilitate microbial growth and oxidation of glucose to GA, and then allow it to evolve freely in order to favour oxidation to $2-\mathrm{KGA}$ as an intermediate product and subsequent formation of 2,5-DKGA. These authors, however, used a medium containing $10 \mathrm{~g} \mathrm{CaCO}_{3} / \mathrm{L}$.

Using G. oxydans NBIMCC 1043, Velizarov and Beschkov ${ }^{31}$ and Beschkov et al. ${ }^{33}$ concluded that the formation of ketoglu- 
conates may be completely inhibited when working without $\mathrm{pH}$ control. These results contradict those of Qazi et al.,${ }^{45}$ but are in agreement with those previously obtained by Weenk et $a l^{43}$ and other authors. ${ }^{13,14}$ Beschkov et al. ${ }^{33}$ examined the effects of setting a constant $\mathrm{pH}$ of 5.5 and adding $\mathrm{CaCO}_{3}$ at the start. Controlling the $\mathrm{pH}$ of the medium resulted in a ketogluconate yield of only $15 \%$ as compared to $80 \%$ obtained by Weenk et al. ${ }^{43}$ The difference may have resulted from the fact that Beschkov et al. ${ }^{33}$ used an initial glucose concentration of $90 \mathrm{~g} / \mathrm{L}$, which was approximately twice that used by Weenk et al. ${ }^{43}$ Consistent with the results of previous studies, ${ }^{43,46}$ the presence of $\mathrm{CaCO}_{3}$ in the culture medium considerably favoured ketoacids production by effect of the low solubility of their calcium salts shifting the chemical equilibria to formation of the acids.

Silberbach et al. ${ }^{47}$ examined the performance of $G$. oxydans strains DSM 3503 and NCIMB 8084 cultured in an orbital shaker under identical conditions in the presence of $\mathrm{CaCO}_{3}$. While the first strain gave GA virtually as the sole product and only very small amounts of 2-KGA and 5-KGA, the second strain produced substantial amounts of ketogluconic acids. Carefully designed experiments with strain NCIMB 8084 conducted in fermentation vessels to ensure better control of $\mathrm{pH}$ and aeration exposed the importance of changing the $\mathrm{pH}$ for optimal performance of the enzymes acting in each stage. Thus, the optimum $\mathrm{pH}$ for GA formation was 4.8 and that for 2,5-DKGA 3.15. Also, maximizing the 2,5-DKGA yield required precise control of the $\mathrm{pH}$ by addition of $\mathrm{NaOH}$ relative to the addition of $\mathrm{CaCO}_{3}$ to the culture medium.

\section{Influence of dissolved oxygen}

The formation of ketogluconates is known to be influenced by the concentration of dissolved oxygen (DO) in the culture medium. Thus, Buse et al. ${ }^{29}$ found DO control to have a strong impact on the formation of, for example, 2,5-DKGA, under the action of $G$. melanogenum ATCC 9937. Thus, keeping the DO concentration at 50 or $100 \%$ the saturation level during the overflow metabolism stage led to a 2,5 -DKGA yield of $80 \%$ in both cases - with some kinetic differences, however. On the other hand, using a DO concentration of $200 \%$ the saturation level had an adverse impact on 2,5-DKGA formation in terms of both kinetics and yield. In the absence of DO control, the concentration of dissolved oxygen rapidly dropped to $2 \%$ and had a highly adverse effect on 2,5 -DKGA production. These results were seemingly the consequence of activity changes in the enzyme gluconic dehydrogenase, which catalyses the first stage in the formation of ketoacids from GA. In fact, Buse et al. ${ }^{29}$ found the enzyme production pattern to differ markedly depending on the degree of oxygen availability at the initial fermenation stage: a low oxygen level delayed production. Therefore, maximizing 2,5-DKGA production seemingly requires keeping the DO concentration in the medium at at least $30 \%$ the saturation level. It should be noted that these authors used a medium containing a high concentration of $\mathrm{CaCO}_{3}(10 \mathrm{~g} / \mathrm{L})$. In any case, oxygen availability is much less influential than other variables such as $\mathrm{pH}$, the initial glucose concentration or the presence of calcium ions, provided the DO concentration exceeds a minimum level. ${ }^{14}$

Some of the previous results, particularly those of the influence of the initial glucose concentration, $\mathrm{pH}$ and calcium content, obtained using synthetic well defined media, have been confirmed also working with complex natural media such as strawberry purée. ${ }^{13,14,48}$ For instance, G. japonicus CECT 8443 transformed selectively glucose into GA without $\mathrm{pH}$ control (changing from 3.3 to 2.4). The preservation of the acid it was directly related with the initial glucose content; when a medium with a low initial glucose concentration (about $17 \mathrm{~g} / \mathrm{L}$ ) was used, the formed GA was subse- quently transformed into ketogluconates, nevertheless, high initial glucose concentrations (about $70 \mathrm{~g} / \mathrm{L}$ ) resulted in no further transformation of GA throughout the process.

\section{Conclusions and future prospects}

This paper is an overview of the influence of the main factors affecting the production of GA, an important compound used in numerous industrial applications, by $\mathrm{AAB}$, namely: $\mathrm{pH}$, initial concentration of glucose in the medium, concentration of $\mathrm{CaCO}_{3}$ added and dissolved oxygen level, in decreasing order of importance.

If the aim is to maximize GA production, then the $\mathrm{pH}$ should be kept below 3.5-4 by either allowing it to evolve freely from the start or using a lower initial value slightly greater than 2.5 in any case. As regards the initial amount of glucose, concentrations in the range $0.9-90 \mathrm{~g} / \mathrm{L}$ facilitate formation and accumulation of GA in the medium; however, higher concentrations inhibit glucose conversion. The presence of $\mathrm{CaCO}_{3}$ facilitates the formation of ketoacids from previously formed GA; this requires mimizing its concentration in the culture medium. Finally, the dissolved oxygen concentration should be kept at $20-30 \%$ the saturation level for optimum results.

Although the previous conditions may differ for each specific strain and culture medium, the variables studied here appear to have a similar influence with different Gluconobacter spp. Therefore, modelling studies for optimizing GA production based on these microorganisms, entail setting the best possible value or range of values for each of the previous variables.

While the results examined here apply to wild strains, advances in the sequencing and targeted molecular engineering of some strains of AAB may open up avenues for obtaning new strains with increased capacities and selectivity for a number of incomplete oxidations, while overcoming some of the restrictions imposed by wild strains.

\section{References}

1. Cañete-Rodríguez AM, Santos-Dueñas IM, Jiménez-Hornero JE, et al. Gluconic acid: Properties, production methods and applications - An excellent opportunity for agro-industrial byproducts and waste bio-valorization. Process Biochem 2016; 51:1891-903.

2. The 2004 OECD list of high production volume chemicals. Paris: Organisation for Economic Co-operation and Development (OECD); 2004.

3. Organisation for Economic Co-operation and Development (OECD). Gluconic acid and derivatives. Screening Information Database (SIDS) 2004; from: OECD Existing Chemicals Database (accessed on September 2016).

4. Climent MJ, Corma A, Iborra S. Converting carbohydrates to bulk chemicals and fine chemicals over heterogeneous catalysts. Green Chem 2011;13:520-40.

5. Milsom P, Meers JL. Gluconic and itaconic acids. In: MooYoung M, Blanch HW, Drew HW, Wang DI, eds. Comprehensive biotechnology, vol. 3 The principles, applications, and regulations of biotechnology in industry, agriculture, and medicine. Oxford: Pergamon Press; 1985. pp 672-700.

6. Roehr M, Kubicek CP, Komínek JC. Gluconic acid. In: Rehm HJ, Reed G, eds. Biotechnology Set. 2nd ed. Germany: WileyVCH Verlag GmbH, Weinheim; 2001. pp 347-362. 
7. Rogers P, Chen JS, Zidwick MJ. Organic acids and solvent production, Part I: Acetic, lactic, gluconic succinic and polyhydroxyalkanoic acids. In: The prokaryotes, A handbook on the biology of bacteria. vol 1: Symbiotic associations, biotechnology, applied microbiology. 3rd ed.: New York: Springer; 2006. pp 511-755.

8. Ramachandran S, Fontanille P, Pandey A, Larroche C. Gluconic acid: properties, applications and microbial production. Food Technol Biotechnol 2006;44:185-95.

9. Anastassiadis S, Morgunov IG. Gluconic acid production. Recet Pat 2007;1:167-80.

10. Singh OV, Kumar R. Biotechnological production of gluconic acid: future implications. Appl Microbiol Biotechnol 2007;75:713-22.

11. Raspor P, Goranovic D. Biotechnological applications of acetic acid bacteria. Crit Rev Biotechnol 2008;28:101-24.

12. Cañete-Rodríguez AM, Santos-Dueñas IM, Torija-Martínez MJ, et al. Preparation of a pure inoculum of acetic acid bacteria for the selective conversion of glucose in strawberry purée into gluconic acid. Food Bioprod Process 2015;96:35-42.

13. Cañete-Rodríguez AM, Santos-Dueñas IM, Jiménez-Hornero JE, et al. An approach for estimating the maximum specific growth rate of some bacteria in complex media without cell concentration data. An example: Gluconobacter japonicus growing in strawberry purée. Biochem Eng J 2016;105:31420.

14. Cañete-Rodríguez AM, Santos-Dueñas IM, Jiménez-Hornero JE, et al. Revalorization of strawberry surpluses by bio-transforming its glucose content into gluconic acid. Food Bioprod Process 2016;99:188-96.

15. Larroche C, Gross JB. Special transformation processes using fungal spores and immobilized cells. Adv Biochem Eng Biotechnol 1997;55:179-220.

16. Trček J, Barja F. Updates on quick identification of acetic acid bacteria with a focus on the 16S-23S rRNA gene internal transcribed spacer and the analysis of cell proteins by MALDITOF mass spectrometry. Int J Food Microbiol 2015;196:13744.

17. García-García I, Gullo M. Acetic acid bacteria: features and impact in bio-applications. Acetic Acid Bacteria 2013;2(s1):1.

18. Gullo M, Giudici P. Acetic acid bacteria in traditional balsamic vinegar. Phenotypic traits relevant for starter cultures selection. Int J Food Microbiol 2008;125:46-53.

19. Gullo M, Verzelloni E, Canonico M. Aerobic submerged fermentation by acetic acid bacteria for vinegar production: process and biotechnological aspects. Process Biochem 2014;49:1571-9.

20. Mamlouk D, Gullo M. Acetic acid bacteria: physiology and carbon sources oxidation. Indian J Microbiol 2013;53:377-84.

21. Matsushita K, Toyama H, Tonouchi N, Okamoto-Kainuma A. Acetic acid bacteria. Ecology and physiology. Japan: Springer; 2016.

22. Mounir M, Shafiei R, Zarmehrkhorshid R, et al. Simultaneous production of acetic and gluconic acids by thermotolerant Acetobacter strain during acetous fermentation in a bioreactor. J Biosci Bioeng 2016;121:166-71.

23. Moyer AJ, Umberger EJ, Stubbs JJ. Fermentation of concentrated solutions of glucose to gluconic acid. Improved process. Ind Eng Chem 1940;32:1379-83.

24. King TE, Cheldelin VH. Oxidations in Acetobacter suboxydans. Biochim Biophys Acta 1954;14:108-16.

25. Olijve W, Kok JJ. Analysis of growth of Gluconobacter oxydans in glucose containing media. Arch Microbiol 1979;121:283-90.
26. Olijve W, Kok JJ. Analysis of the growth of Gluconobacter oxydans in chemostat cultures. Arch Microbiol 1979;121:29197.

27. Levering PR, Weenk G, Olijve W, Dijkhuizen L, Harder W. Regulation of gluconate and ketogluconate production in Gluconobacter oxydans ATCC 621-H. Arch Microbiol 1988;149:534-9.

28. Kulhánek M. Microbial dehydrogenations of monosaccharides. Adv Appl Microbiol 1989;34:141-82.

29. Buse R, Qazi GN, Onken U. Influence of constant and oscillating dissolved oxygen concentrations on keto acid production by Gluconobacter oxydans subsp. melanogenum. J Biotechnol 1992;26:231-44.

30. Träger M, Qazi GN, Buse R, Onken U. Comparison of direct oxidation by Gluconobacter oxydans subsp. suboxydans and Aspergillus niger in a pilot scale airlift reactor. J Fermen Bioeng 1992;74:274-81.

31. Velizarov S, Beschkov V. Production of free gluconic acid by cells of Gluconobacter oxydans. Biotechnol Lett 1994;16:71520.

32. Velizarov S, Beschkov V. Biotransformation of glucose to free gluconic acid by Gluconobacter oxydans: substrate and product inhibition situations. Process Biochem 1998;33:527-34.

33. Beschkov V, Velizarov S, Peeva L. Some kinetic aspects and modelling of biotransformation of D-glucose to keto-D-gluconates. Bioprocess Eng 1995;13:301-5.

34. Matsushita K, Toyama H, Adachi O. Chapter 4. Respiratory chains in acetic acid bacteria: membrane-bound periplasmic sugar and alcohol respirations. In: Respiration in Archaea and Bacteria. vol. 16. Advances in photosynthesis and respiration; 2004. pp. 81-91.

35. Deppenmeier U, Ehrenreich A. Physiology of acetic acid bacteria in light of the genome sequence of Gluconobacter oxydans. J Mol Microbiol Biotechnol 2009;16:69-80.

36. Saichana N, Matsushita K, Adachi O, et al. Acetic acid bacteria: a group of bacteria with versatile biotechnological applications. Biotechnol Adv 2015;33:1260-71.

37. De Muynck C, Pereira CSS, Naessens M, et al. The genus Gluconobacter oxydans: comprehensive overview of biochemistry and biotechnological applications. Crit Rev Biotechnol 2007;27:147-71.

38. Matsushita K, Toyama H, Adachi O. Respiratory chains and bioenergetics of acteic acid bacteria. Adv Microb Physiol 1994;36:247-301.

39. Kostner D, Luchterhand B, Junker A, et al. The consequence of an additional NADH dehydrogenase paralog on the growth of Gluconobacter oxydans DSM3504. Appl Microb Cell Physiol 2015;99:375-86.

40. Krajewski V, Simic P, Mouncey NJ, et al. Metabolic engineering of Gluconobacter oxydans for improved growth rate and growth yield on glucose by elimination of gluconate formation. Appl Environ Microbiol 2010;76:4369-76.

41. Shinagawa E, Matsushita K, Adachi O, Ameyama M. DGluconate dehydrogenase, 2-keto-D-gluconate yielding, from Gluconobacter dioxyacetonicus: purification and characterization. Agric Biol Chem 1984;48:1517-22.

42. Toyama H, Furuya N, Saichana I, et al. Membrane-bound, 2keto-D-gluconate-yielding D-gluconate dehydrogenase from "Gluconobacter dioxyacetonicus" IFO 3271: molecular properties and gene disruption. App Environ Microb 2007;73:65516.

43. Weenk G, Olijve W, Harder W. Ketogluconate formation by Gluconobacter species. Appl Microbiol Biot 1984;20:400-5.

44. Seiskari P, Linko YY, Linko P. Continuous production of glu- 
conic acid by immobilized Gluconobacter oxydans cell bioreactor. Appl Microbiol Biot 1985;21:356-60.

45. Qazi GN, Parshad R, Verma V, et al. Diketo-gluconate fermentation by Gluconobacter oxydans. Enzyme Microb Tech 1991;13:504-7.

46. Stadler-Szöke A, Nyeste L, Hollo L. Studies on the factor affecting gluconic acid and 5-ketogluconic acid formation by Acetobacter. Acta Aliment 1980;9:155-72.
47. Silberbach M, Maier B, Zimmermann BM, Büchs J. Glucose oxidation by Gluconobacter oxydans: characterization in shaking-flask, scale-up and optimization of the $\mathrm{pH}$ profile. Appl Microbiol Biot 2003;62:92-8.

48. Sainz F, Navarro D, Mateo E, et al. Comparison of D-gluconic acid production in selected strains of acetic acid bacteria. Int $\mathrm{J}$ Food Microbiol 2016;222:40-7. 